\title{
COCHABAMBA EN FRAGMENTOS: UN ACERCAMIENTO AL FENÓMENO DE LOS BARRIOS CERRADOS
}

Juan E. Cabrera, Andrés Escobar y Micaela Ugarte

\section{RESUMEN}

Este trabajo presenta una primera aproximación al estado de situación de los barrios cerrados en el área metropolitana de Cochabamba. Con el objeto de comprender las características de la ciudad fragmentada así como las condiciones físico-espaciales, sociales, simbólicas y motivaciones que parte de la población cochabambina tiene para habitar conjuntos habitacionales segregados, el artículo revisa y reflexiona el proceso de diferenciación socio espacial en las ciudades occidentales y Cochabamba hasta llegar al fenómeno de los barrios cerrados. Los resultados del estudio ofrecen una perspectiva general sobre este fenómeno en la urbe metropolitana, la situación de la institucionalidad, así como los elementos que caracterizan los barrios cerrados del área de estudio.

Palabras Clave: Área Metropolitana de Cochabamba, Barrios Cerrados, Desigualdad Urbana, Diferencia Socio Espacial, Fragmentación, Segregación.

DOI: 10.23881/idupbo.019.2-6e 